\title{
Knowledge Transfer in ERP Implementation Universitas Islam Indonesia Story
}

\author{
Fitriati Akmila*
}

\begin{abstract}
Enterprise resource planning (ERP) is an integrated software application in enterprise system that is used to manage organizations' resources. Currently, SAP is the most widely used of ERP systems package in the market.

This paper is a case study based on the ERP implementation at the Universitas Islam Indonesia (UII) in Yogyakarta, Indonesia. This study sees ERP implementation in knowledge transfer perspective in which explains the process of bringing explicit business processes to the organization.

There are four stages in understanding the knowledge transfer process at UII: initiation, implementation, ramp up, and integration. The most crucial stages are ramp up and integration. During the ramp up organization adopt the "best processes" by configuring their environment so that explicit knowledge are easily transferred to the organization. In the integration, the knowledge is internalized into the organization and seen as a gradual process for the new practices to become part of the new reality of the organization.
\end{abstract}

Keywords: Knowledge Transfer, UII, ERP, SAP

\section{Introduction}

Enterprise system is a set of information system tool that many organizations use to enable information flow inside and between business processes in the organizations (Pearlson and Saunders 2006a). The most common discussed system tool in enterprise system is Enterprise resource planning (ERP). ERP is an integrated software application in enterprise system that is used to manage organizations' resources. ERP combines business management process and information technology concept to be integrally (Basoglu et al. 2007). There are many vendors that play as ERP providers, such as SAP, Oracle, People Soft, and JD Edward. Currently, SAP is the most widely used of ERP systems package in the market. It contains 1000 business reference models from different industries that are mapped into organization's business (Lee and Lee 2000).

* Dosen Fakultas Ekonomi UII 
Business organization needs ERP to solve it complex business problem. University as a service organization now need an ERP to manage their organization resources. Although the size of the business is not as complex as profit organization but the idea of implementing ERP is important as the university needs to manage its internal information as well as to handle vendors and customers problems.

Since ERP consists of integrated modules in a software package, it is forced the organization to redesign its business processes. These processes require a lot of work and conflict within the organizations especially with the changes in the organization structure (Pearlson and Saunders 2006a). In order to solve the conflict, the knowledge transfer process is important as a mediated process of moving and integrating knowledge from ERP as a software package with its architecture to the legacy value that the business already familiar with.

Knowledge transfer is defined as a transmission of knowledge and conveying it from one source to the other (Awad and Ghaziri 2004). The sender and the recipient are the parties involved in conveying the knowledge. The sender of knowledge in ERP is ERP software itself and the recipient is the users who used the ERP software as an integral part of their business process. The knowledge transfer in ERP has two characteristics. Firstly, it is a computer package-based knowledge transfer in which only coded business processes are transferred. Secondly, the scope of knowledge transfer is company wide process, which means all organizations business functions are connected to each other Lee and Lee (2000) .

This paper is a case study based on the ERP implementation at the Universitas Islam Indonesia (UII) in Yogyakarta, Indonesia. The case description is based on an in-depth analysis of the early stages or ERP implementation in UII. The objective of this paper is to describe the process of change in the organization from the legacy system to ERP, the types of knowledge transfer during an ERP implementation. Moreover, it explores the problem during the implementation process and the organization efforts to solve those problems.

The remainder of this paper is structured as follows. The second section is the literature review related to enterprise system issues and knowledge transfer. The third section is the research method. The fourth section is the analysis. Fifth section is the analysis and finally the last section discusses the results and presents conclusions.

\section{Literature Review}

\section{Enterprise Resource Planning}

Enterprise System or Enterprise Resource Planning (ERP) is an integrated software application used to manage organizations resources Davenport (1998). 
The architecture of an ERP is constructed on one database, one application, and a unified interface across the entire enterprise. Therefore, an entire organisation is able to operate under one application standard which serves human resources, accounting, sales, manufacturing, distribution, and supply chain management functions (Al-Mashari et al. 2003). Furthermore, Pearlson and Saunders (2006a) mentioned six characteristics embedded in ERP: (1) Integration, in which information system is integrated and flows throughout the company. (2) It consists of modules such as manufacturing, financial, human resources and sales. (3). ERP is a commercial package that requires a long term relationship with software vendors and it should be modified on a continuing basis to meet organization's needs. (4) It is a best practice and sometimes causes business process reengineering when ERP is applied in an organization. (5) Some system customization required as ERP integrated with the legacy systems. (6) Evolving, in which ERP system is still being developed and designed to be able to interact iwith other system such as supply chain management software.

ERP brings advantages into the organization; (1) All modules in ERP can communicate each other through a stand-alone system (2) The integration of enterprise systems is important tools for organization to centralize its operations and decision making through standardization. Standardization allows users to get the same information at the same time. This process avoids data redundancies (Pearlson and Saunders 2006a).

More over, based on research by Berchet and Habshi (2005) in Alcatel, ERP gives contribution to the firm as the following; (1) Integrated Information system which the firm can covers all its functionalities using the same tools, (2) Tight control of physical flows, tough control of information and financial flows,(3) ERP provides reliable information and data coherence because the information is traceable, (4) Ease and speed of accessing information caused by personalised access and a single sign on that creates significant time savings and productivity gains, (5)Unique and identical information in real time for all users. ERP systems allow users to get the same information at the same time. This process avoids data processing redundancies, (6) more rigours in data management, the firm can give more precise data and information concerning the customers and top management demands.

Despite the benefits, ERP also has disadvantages. The followings are the disadvantages: (1) Integrated modules forced organizations to redesign their business processes. These processes require a lot of efforts and create conflicts within the organizations especially with the changes in the organization structure. (2) As the wide scope of ERP and its close system connectivity to all modules as well as its functions make the ERP software very costly (Davenport 1998). 
According to Meta group, the total cost of ownership of enterprise system is ranging from $\$ 400,000$ to $\$ 30$ million (Pearlson and Saunders 2006a).

\section{2. $S A P$}

SAP stand for System Analysis and Program development. It was founded in Germany by five former IBM employees in 1972. Their objective was to develop standard application software for real time processing (Brinkmann and Zeilinger 2001). SAP's software concept is designed to meet the information requirements of companies throughout the world. Currently, the architecture system that developed in SAP is called as SAP R/3 that works based on a multilevel client-server concept. The applications or modules in SAP R/3 are based on a general business model. The general models are mapped through modules that covers the following areas of business: Financial accounting (FI), Controlling (CO), Executive information system, Material Management (MM), Production Planning (PP), Sales and Distribution (SD), Quality Management (QM), Service Management (SM), Plant Management (PM), Project Planning (PS), Human Resources Management (HR), Office and Workflow function. SAP R/3 is also supplemented with software development tools, for example ASAP which is used to monitor the system in day-to-day operation at the customer sites (Brinkmann and Zeilinger 2001). Customization is needed in SAP implementation. Customization is a process of modifying standard software so that it meets to company-specific requirement. Customizing in SAP R/3 is a process of the implementation of SAP modules separately from each others and adapts them to the requirements of a business. The process is quick, effective, and cost efficient (Brinkmann and Zeilinger 2001).

\section{Knowledge transfer}

Knowledge is a summary of information after it is connected with other information and compared to what is already known. For instance books contain information and it becomes knowledge when a person understands it content and apply those information (Daft 2007). In addition, Pearlson and Saunders (2006b) defined knowledge as a combination of information, experiences, rules, and values. The concepts of knowing such as "knowing what", "knowing how", and "knowing why" are embedded in the concept of knowledge.

There are two types of knowledge which are explicit knowledge and tacit knowledge. Explicit is a systematic knowledge that can be codified, written down, and transferred to others in documents or other digital means. Explicit knowledge sometimes refers to "knowing about". While tacit knowledge is based on personal experience, rule of thumb, intuition, and judgment. It includes 
professional know-how and expertise, individual insight and experience, and creative solutions that are hard to communicate and pass on to others. Tacit knowledge is equated with "knowing how" (Daft 2007). Explicit knowledge can be easily collected and organized whereas tacit knowledge are difficult to captured, formalized and transferred throughout organizations (2007; Pearlson and Saunders 2006b).

Nonaka and Takeuchi (1995) defined explicit knowledge as a knowledge that is transmittable in a formal, systematic way. This knowledge can be "processed" by a computer, transmitted electronically or stored in a database. While tacit knowledge is associated with individual experiment and difficult to code. As it is subjective and intuitive, tacit knowledge is not easy to be processed in any systematic or logical manner.

Knowledge transfer as regard to ERP implementation is about transmitting knowledge when business processes are mapped and imitated. Business processes are mapped through the solution package that ERP provides for business problems. Therefore, knowledge transfer in best practice is defined as dyadic exchanges of organizational knowledge between a source and a recipient. There are four stages of knowledge transfer process regarding best practices (Szulanski 2000). Four stages are described as follows:

- Initiation: This stage consists of events that lead to the decision to transfer.

- Implementation: This stage starts with the decision to proceed. During this stage, resources flow between the recipient and the source. Implementation activities diminish after the recipient begins using the transferred knowledge.

- Ramp-up: This stage starts when the recipient begins using the transferred knowledge. During this stage, the recipient is likely to use new knowledge ineffectively but gradually improves performance to satisfactory level.

- Integration: This stage starts after the recipients achieve satisfactory results with the transferred knowledge. The transferred knowledge becomes routines and institutionalizes to become the new reality of the organization.

Brown and Duguid (1991) classified business processes into two types, namely, canonical and non canonical. Based on these classification, knowledge transfer in ERP then involved canonical (explicit) and non canonical (tacit) business processes. Canonicals based on an abstract representation of the organization itself. While non canonical processes are what actually happen during the work. Canonical process covers the transferring of explicit knowledge embedded in ERP software package. ERP software is explicit because it has reference models that contain formal chain of activities represented by process modelling tools. 
These processes are visible and explicitly coded in the software (Zander and Kogut 1995). Secondly, non canonical processes of tacit knowledge transfer. These processes are related to difficult-to-migrate portion of organizational knowledge which is deeply embedded in complex social interactive relationships within an organization and have a property of stickiness (Szulanski 2000). The difficulties in migration process occur as ERP is not only a software but also an organizational structure that affects how people work (Hanseth and Braa 1998 as cited by (Lee and Lee 2000)). Therefore, ERP implementations convey business knowledge related to the business processes and this type of knowledge is not easily transmitted to the adopting organization.

The canonical process in ERP is referred to the implementation process in which the knowledge of ERP system is easily mapped and transferred. Conversely, the integration process is a non canonical process that involved merging process of the ERP models to the existing values within the organization. The conflict occurs during the integration as ERP is the new value which interacts with the existing or current values of the organization. The process of internalization of ERP into the business is important as for the organizational members to appreciate the new value of the system (Lee and Lee 2000).

Following the theoretical framework above, the analysis of this study will be discussed using the four stages defined by Szulanski (2000) and canonical and canonical business processes perspective developed by Brown and Duguid (1991) which then adapted by Lee and Lee (2000) to analyse the knowledge transfer process in the University of Nebraska. Lee and Lee (2000) developed their research analysis through the following research model; firstly, canonical knowledge is transferred based on reference models accompanied by business rules. Secondly, canonical knowledge is received and accepted in the organization but the business rules associated with the reference models begin to conflict with the existing business fundamentals of the organization. Thirdly, the organization tries to internalize the business values from the ERP package with its existing business practice.

\section{Research Method}

This paper is a case study which provides empirical inquiry that investigates contemporary phenomenon within its real life context. Case study is useful when the boundaries between phenomenon and context are not clearly evident as quoted by Punch (2005) from Yin (1994). In this paper, the ERP implementation is a contemporary phenomenon that will be studied in the real life context in UII. Moreover, the research question looks at the knowledge transfer process in ERP implementation in the organization. 
The data for the case study were collected through two sources, namely interviews and documentation analysis. Interviews became the main form of the data collection, supported by a number of available documentations.

Interviews were in the form of email and phone interviews, in which a number of questions were asked. Data were collected via email attachments (within email interviews) and note-taking (within phone interviews). Five (5) individuals were interviewed for their experiences during the early implementation process of SAP. Two (2) were project managers; One (1) was steering committee who is currently still supervising the implementation process, and two (2) were operational users. Supporting data for this study were also collected through documentation analysis.

Since the author had the opportunity to interview the key respondent within UII, internal documentations such as project plans, the ERP model and structure, business process, and some notes of meeting can be collected and examined. Information obtained from those documents was very helpful for case analyses.

There were a number of difficulties experienced during collecting data for this study, such as time constraint and uncertainty in getting response(s) from the participants due to their personal affairs. In addition, distance made it difficuit to conduct face-to-face interviews with the participants. Therefore, the phone and email interviews were chosen.

\section{The Case Study: Universitas Islam Indonesia (Islamic University of Indonesia)}

Universitas Islam Indonesia or UII founded in 1945 is a private university located in Yogyakarta, Indonesia. The university offers undergraduate programs in eight faculties with twenty one study programs, six different master programmes (Management, Law, Islamic Studies, Law, Civil Engineering, Psikologi, and Industrial Engineering) and two doctorate programmes in law and economics. The number of full time students are 17,846 in 2007. The students come from different parts of Indonesia. UII also has several business units such as printing companies, hospitals and pharmacies.

In 1994, UII financial accounting system was based on cash basis ${ }^{1}$ in recording its transaction records. The problem with this system is that UII could not identify the number of its inventory since all inventory was recognised as expenses. The lack of control of inventory caused UII lost some of its assets.

Realizing that the cash basis could not meet the requirement for providing

In Accounting term cash basis means the effects of transacions or other events happen when cash or its equivalent is received rather than when the transactions or other events occur Trotman, Ken and Michael Gibbins. 2005. Financial Accounting: an Integrated Approach. Thrid Edition: Thomson Learning.. 
standard information for financial reporting which used accrual basis ${ }^{2}$, then in 1997, UII developed in house standardized financial information system called SIMKEU (Financial Information System). Each UII faculty and department had SIMKEU for its financial system. Although this system made some improvements with the automation of the system, however, SIMKEU still had weaknesses in which the recording system in the transaction used cash basis system and it was not connected between each faculty and UII as an enterprise.

With the growing number of faculties and students, encouraged UII to create SIMAK (Academic Information System), SIMIN (Inventory Information System), and SIMSDM (Staff and Human Resource System). Unfortunately SIMKEU, SIMAK, SIMIN, and SIMSDM were not connected to each other through the system. The control of inventory was getting more difficult since the system could not provide real time data and time consuming in detecting the fraud due to the difficulty of accessing the data. Futhermore, although SIMKEU could provide financial report of UII income and expenditure yet, it was difficult to trace the expenditure flow througout UII faculties and business units.

Realizing the complexities of its internal problems with integration of all information system, in 2005 UII tried to build in house integrated system. However, this projects failed to solve the complexity of UII business processes. After two years having had problems in building in house system, in 2006 UII . decided to buy SAP ECC 6.0. This decision was fully supported by the top management, as he had mentioned that:

...With the development of UII as an education institution that has several business units, real time and accuracy of financial information is strongly important for decision making process. The decision to buy SAP is a way of solving problems that occurs as a results of the inability of the current system to process fast information and control financial activities such as inventories.

UII started to use SAP in February 2007. After one year (February 2008) of SAP R/3 implementation, UII begins to gain benefits as follows; (1) integrated information system, (2) reliable information data coherence as the information is traceable, (3) Ease and speed of information access by the top management for controlling purpose. These benefits are similar with the findings in Alcatel

2 Accrual basis refers to the method of making a comprehensive financial measurement and $\because$ position by recognising economic events regardless of when cash transaction happen. In

$\therefore$ accrual basis, revenues and expenses are related in the the accounts in the accounts in the period to which they relate Ibid.. 
Fitria Akmila, Knowledge Transfer in ERP Implementation: Universitas Islam.........

by Berchet and Habchi (2005) . Figure 1, shows the current integrated system in UII. This integration system is called SIAT (Integrated Accounting Information System).

Integrated Information System at UII

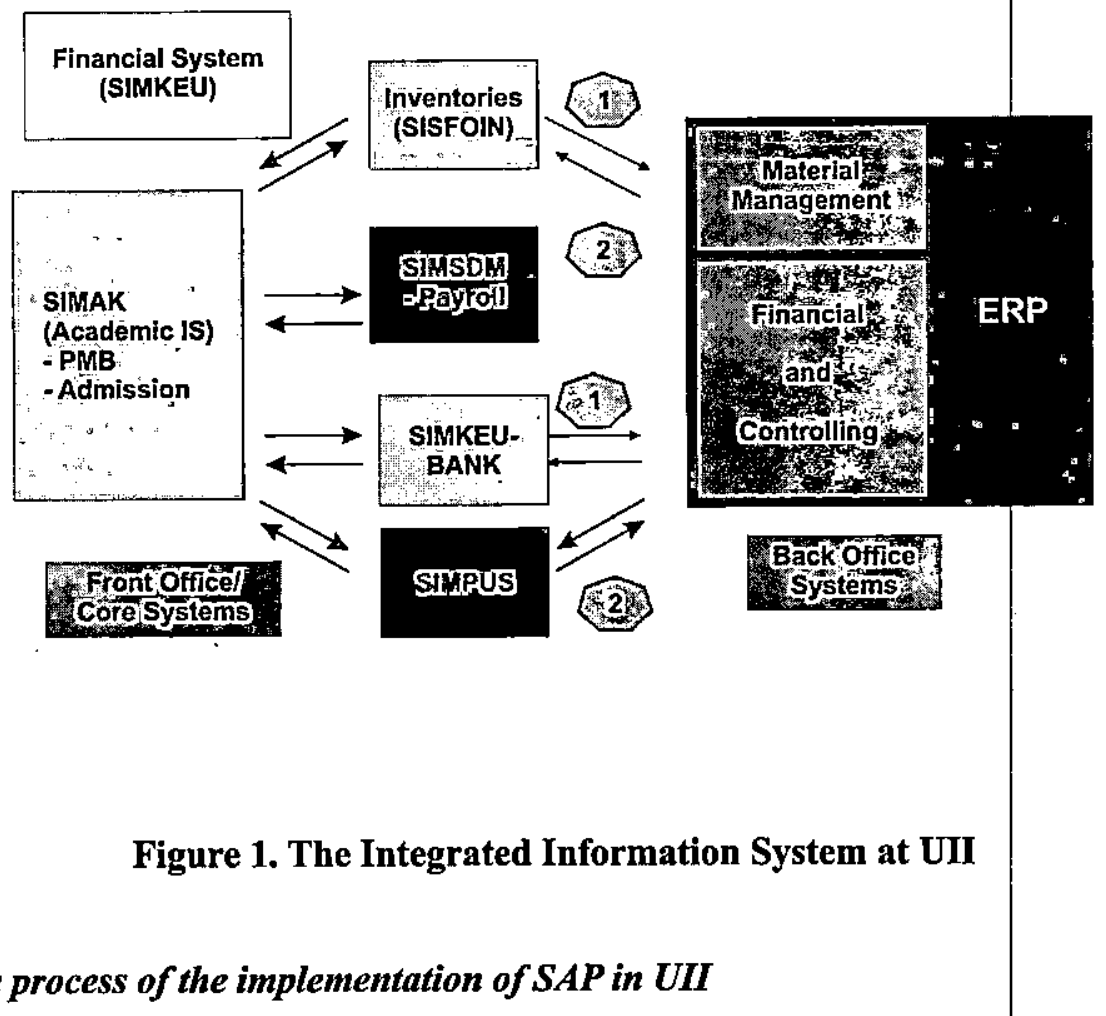

UII started to implement SAP R/3 system in 13 February 2007. The ERP system comprises of three modules: (1) Financial Accounting (FI) consists of General Ledger, Account Payable, Account Receivable, Asset and Interface to UII Internal system, (2) Controlling Module (CO) consists of Cost Centre Accounting, Profit Centre Accounting and Internal Order, and (3) Material Management (MM) consists of Consumption Based Planning, Purchasing, Inventory Management, and Invoice Verification.

The set-up process of SAP implementation took 119 days from 14 August 2006 to 13 February 2007. This set-up process was done by UII-SAP team which has been pointed by the top management. UII-SAP team collaborate with SAP consulting firm in setting up the new system. Four steps of setting up SAP into the organization are illustrated as in Figure 2. 


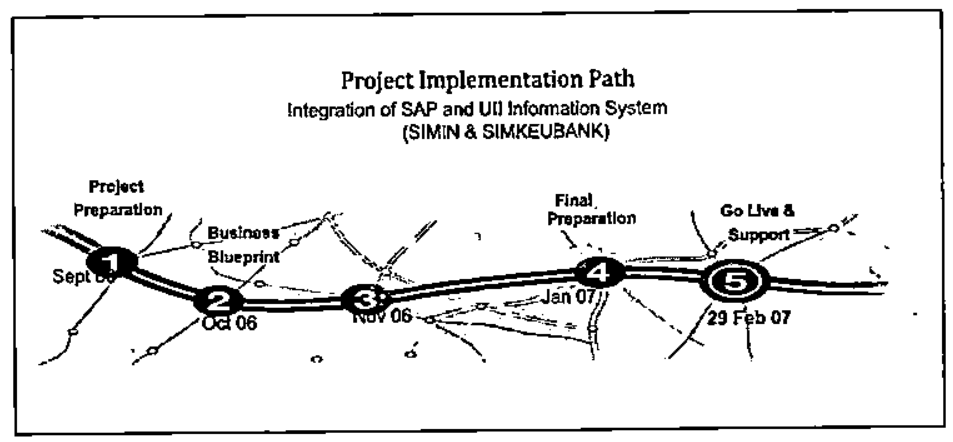

Figure 2. Project Implementation Path of SAP in UII

The set-up of project implementation consisted of five stages of activities: project preparation, business blueprint, realization, final preparation, and go live and support. The summary of activities during the five stages described as in figure 3 .

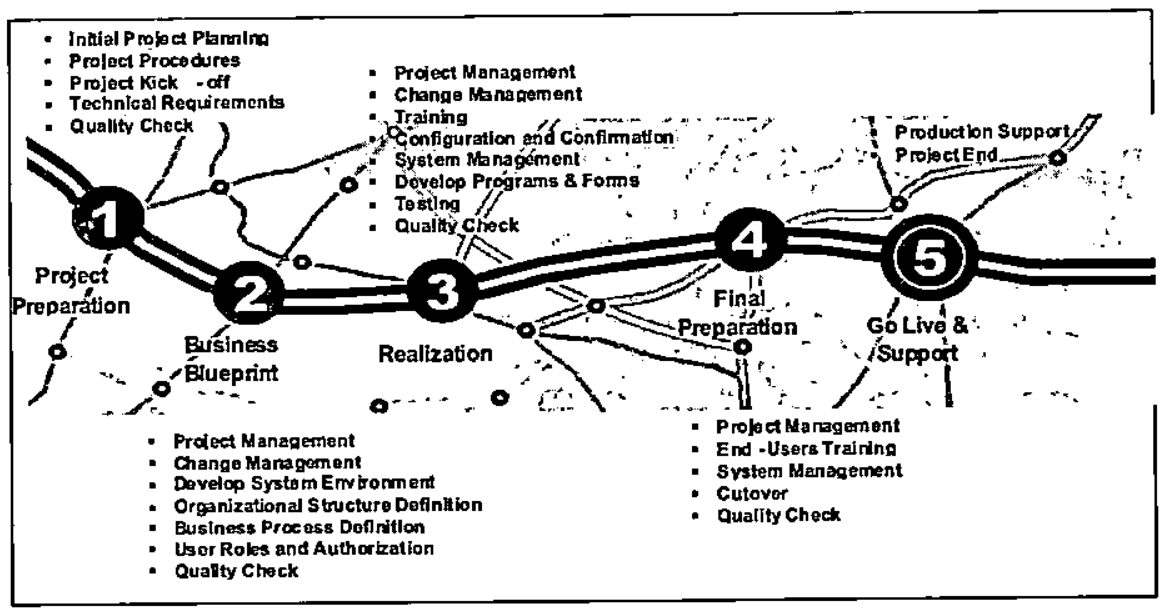

Figure 3. The summary of set-up project implementation activities

\section{Analysis}

There are four stages of knowledge transfer as outlined by Szulanski (2000). The stages of transfer process of ERP in UII are described as the following:

\section{Initiation and Implementation}

The initiation and implementations stages are comprised of all events that lead to create transition guides from UII legacy system to the new system. Those two processes took place in the project preparation and business blueprint processes. 
Project preparation took 31 days. In project preparation, the activities are mainly checked the project plan instruments such as detailed project plan, project charter, and project issue log. Business blueprint is created within 25 days. In this process, the change management and new adopted organization structure is constructed. After project blue print is clearly defined, the next step is realization (26 days) which some activities such as customizing documentation and training for the trainers (UII-SAP team) are conducted.

\section{Ramp up}

Ramping up process started in the final preparation process (17 days) in which new organization structure role and responsibilities, user manual are produced and used for training the end user. The end user training conducted in 10 (ten) days. The end users are staff in the finance and procurement departments. The final set-up process was go live and support (20 days) in which the SAP system were running and supported by the help desk is provided for the system assistance.

Ramp-up stage is about transferring canonical or explicit knowledge from ERP as a source of knowledge to the users as the recipient. Canonical embedded in ERP software package and it reference models that contain formal chain of activities represented by process modelling tools (Zander and Kogut, 1995 as cited by Lee and Lee (2000)) . During ramp up stage (final preparation and go live and support), the users (staff) begin to received the transferred knowledge. In this stage the users or recipients concerned with identifying and using the new knowledge they received from the training. Through the assistance from UII-SAP team and help desk, the users gradually improve their performance and ramp up toward satisfactory level.

\section{Integration}

Integration process in ERP implementation is seen as a continuing process of using SAP. However, some problems occurred during the first month of the system implementation. This is due to unfamiliarity of the staff with the accrual basis inside SAP financial and some errors happened. For example; the accounting staff only recorded cash transaction, non cash transaction was not recorded in the system and error in journaling the transaction account since the account descriptions were in English term.

Based on interviews with the project manager, those problems arose as incompetency of staff UII has in certain aspects, such as follows:

- Most staffs in finance and procurement department are graduated from senior high school, few were holds bachelor degree unfortunately they did not have accounting background. With the background that staffs 
have, it is easier to learn the cash basis framework rather than accrual basis concepts.

-. Lack of English language competency so that it is not easy for the staff to operate SAP because SAP used English language as a medium of its system language.

Therefore, additional training is conducted to overcome the problems as stated above. Before additional training was conducted, the UII-SAP team performed tests to check the staff ability in understanding the SAP system. The results were surprisingly low with only six staff $(15 \%)$ in finance department and four staffs (7.27\%) did meet the requirement. After this test second training was conducted by the SAP team to improve the competency of the staff. Following the second training, the second test again was conducted to check the improvement. The results showed slightly increase in the number of staff who understand how SAP system works. The detailed results are shown in figure 3 below.

Financial Accounting (FI)

\begin{tabular}{|c|c|c|}
\hline Score & First test & Second test \\
\hline 90 & 1 & 3 \\
\hline 80 & 2 & 2 \\
\hline 70 & 3 & 6 \\
\hline$<70$ & $34(85 \%)$ & $29(72.5 \%)$ \\
\hline
\end{tabular}

Material Management (MM)

\begin{tabular}{|c|c|c|}
\hline Score $y^{\text {y }}$ & 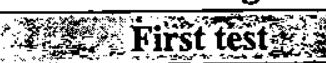 & (2) Second test th \\
\hline$\geq 70$ & 2 & 3 \\
\hline 60 & 2 & 5 \\
\hline$<60$ & $51(92.73 \%)$ & $47(85.45 \%)$ \\
\hline
\end{tabular}

\section{Figure 4. The result of the staff test in using $\mathrm{SAP}^{3}$}

Training the staffs is a continuos process in SAP implementation in UII. The purpose of this activity is to be able to optimize SAP-ERP system as a current business process in UII. Instead of training, rewards also given to staff that were able to perform better in the new integrated system. Moreover, UII-SAP team also maintain and fully support all the problems in the integration by fully used the help desk function. The help desk plays an important role for providing solution for technical problems error.

The standard mark that to meet the requirement for operating SAP system is less than or equal to 70. 
The integration process is a non canonical process that involved merging process of the ERP models to the existing values within the organization. During the integration, canonical knowledge is received and accepted in the organization but the business rules associated with the reference models begin to conflict with the existing business fundamentals of the organization (Lee and Lee 2000). In UII, canonical knowledge from SAP merging into UII-SAP system and began to conflict with the current system (SIMKEU). The problems with staff are happen because of unfamiliarity with the "accrual system" that SAP has. This was natural b'ecause the culture of "cash system" has been there for ten years (SIMKEU existed in UII from 1997 to 2007). This is similar with Hanseth and Braa (1998) observation that the difficulties in migration process occur as ERP is not only a software but also an organizational structure that affects how people work. In this case, users are required to follow the explicit business processes embedded in the software package. Users are restricted by the nature of the system and the system became emerging infrastructure that governs what they are doing (Hanseth and Braa, 1998 as cited by (Lee and Lee 2000)).

As illustrated in the data, during integration, as staff had problems with the new system, more tests and trainings are conducted as organizational efforts to solve the conflict as the new business knowledge imposed to the organization. With continuous training and support by the UII-SAP team staff began to understand how the new system worked.

As can be inferred from UII integration process is that gradually the new practices (UII-SAP system) become part of the reality of the organization. The efforts to solve the problem with the staff are ways to institutionalize to new system to become integral part of the organization. This is similar with Berger and Luckman (1996) observation as cited by Szulanski (2000) that as the new practice become institutionalized, it is taken-for-granted become reality of the organization. Moreover, Lee and Lee (2000) observed that the process of institutionalization is similar with the process of internalization of ERP into the business. In this process new system is getting important and organizational members appreciate the new value of the system.

Currently, the SAP implementation in UII is still guided by UII-SAP team. It is hope that in the near future UII with its internal resources can fully used the integrated system process provided by SAP as UII competitive advantage.

\section{Conclusion}

Knowledge transfer in best practice is defined as dyadic exchanges of organizational knowledge between a source and a recipient (Szulanski 2000). Transferring both tacit and explicit knowledge is vital in organization. The reason 
for this is that without the conveying the knowledge, business goal cannot be achieved. In short, this paper illustrates the case study in the knowledge transfer in ERP implementation in Universitas Islam Indonesia (UII), Yogyakarta, Indonesia. Previously UII build its own in house information system. In February 2007 UII started to use SAP as a tool for UII's integrated information system. The writer used two approaches in understanding the process of transferring the knowledge. Firstly, the writer looked at the transfer process through four stages developed by Szulanski (2000). The stages were initiation, implementation, ramp up, and integration. Secondly, analysed the integration process through canonical and non canonical lenses as developed by Brown and Duguid (1991)

In conclusion, ERP implementation is different from other technologies regarding the extent to which an ERP infuence organizational practice. From a knowledge transfer perspective ERP implementation is seen as a process bringing explicit business processes to the organization. This study sees ERP implementation process should be understood though the stages of knowledge transfer. The most crucial stages are in the ramp up and integration stages. During the ramp up stage organization adopt the "best processes" (explicit knowledge) by configuring their environment and provide tools so that explicit knowledge are easily transferred to the organization. In integration, the knowledge is internalized into the organization. Problems arose as new knowledge conflicted with the existing business rules. As a result, organizational capabilities and efforts are needed for solving the problems. Finally, integration is also seen as a gradual process for the new practices to become part of the reality of the organization. 
Fitria Akmila, Knowledge Transfer in ERP Implementation: Universitas Islam........

\section{References}

Al-Mashari, Majed, Abdullah Al_Mudimigh and Mohamed Zairi. 2003. "Enterprise Resouce Planning: Taxonomy of Critical Factors." European Journal of Operational Research:352-364.

Awad, Elias M. and Hassan M. Ghaziri. 2004. "Knowledge Transfer and Knowledge Sharing." In Knowledge Management.Upper Saddle River: Pearson Prentice Hall.

Berchet, Claire and Georges Habchi. 2005." "The Implementation of an ERP System: An Industrial Case Study." Computers in Industry(56):588 - 605.

Brinkmann, Sandra and Axel Zeilinger. 2001. SAP R/3 Financial Accounting: Making It Work for Your Business: Pearson Education.

Brown, Hohn Seely and Paul Duguid. 1991. "Organizational Learning and Communities of Practice: Toward a Unified View of Working, Learning, and Innovation

“Organization Sciance Vol.2, No.1, February 1991:40 - 57.

Daft, Richard L. 2007. Organization Theory and Design. ninth Edition: Thomson South Western.

Davenport, Thomas H. 1998. "Putting the Enterprise into the Enterprise System." Harvard Business Review(July - August 1998):121-131.

Lee, Zonky and Jinyoul Lee. 2000. "An ERP Implementation Case Study from Knowledge Transfer Perspective." Journal of Information Technology 15:281 - 288.

Pearlson, Keri E. and Carol S. Saunders. 2006a. "Information Technology and Changing Business Processes." In Managing and Using Information Systems: A Strategic Approach. Third Edition: John Wiley

Punch, Keith F. 2005. Introduction to Social Research: Quantitative and Qualitative Approach. Second Edition: Sage Publication.

Szulanski, Gabriel. 2000. "The Process of Knowledge Transfer: A Diachronic Analysis of Stickiness." Organizational Behavior and Human Decision Processes 82(1 May):9 - 27. 